\title{
Evaluation of Talud Technical Planning on River Regency of Aceh Singkil
}

\author{
Darlina Tanjung ${ }^{1}$, Jupriah Sarifah $^{1}$, Bangun Pasaribu ${ }^{1}$, Marwan Lubis ${ }^{1}$, Anisah Lukman ${ }^{1}$, Abdurrozzaq \\ Hasibuan $^{2}$ \\ ${ }^{1}$ Department of Civil Engineering, Faculty of Engineering, Universitas Islam Sumatera Utara, Medan, Indonesia \\ ${ }^{2}$ Department of Industrial Engineering, Faculty of Engineering, Universitas Islam Sumatera Utara, Medan, Indonesia \\ *Corresponding author E-mail: darlinatanjung@ft.uisu.ac.id
}

\begin{abstract}
Dynamics that occur in the city of Singkil impact on the development of the city both on socioeconomic aspects as well as in the physical manifestation of talud facilities, which can spur an increase in productivity of a region and the functioning of infrastructure of a city well and smooth. Effect of retaining wall against cliff reinforcement that can protect embankment or beach. By knowing the magnitude of the effect of the safety factor due to the slip, bolster, and the decrease due to the consolidation of the clay layer and the load of the embankment as well as the amount of time of the decline. The crumbling factor (FS guling $=14.97$ ) is greater than the safety factor, for the stability of the slip where the maximum force, where the only force of thrust causing the active horizontal force component $(\mathrm{Pa}=0.333)$ results in a FS (slip) greater than the safety factor of stability to the carrying capacity, the eccentricity value $(e=-0.081)$ more than $1 / 6$ then the qmin value becomes positive, since the value of e $<1 / 6$, and the FS yield of soil bearing capacity (FS (carrying capacity) $=$ 162.122) this value is greater than FS security means the talud safely holds load carrying capacity, safe against bolsters and slip.
\end{abstract}

Keywords: Security Factor, Carrying Capacity, Ground Soil.

\section{Introduction}

The dynamics that occurred in Singkil City has an impact on the development of the city both on the socio-economic aspect and in the physical manifestation of the talud facilities, which can spur the productivity improvement of a region and the functioning of the infrastructure infrastructure of a city well and smoothly. Effect of retaining wall against cliff reinforcement that can protect embankment or beach[1], [2].

From the above conditions it is necessary a Technical Planning Talud Aceh Singkil District[3], [4]. As a mature and well planned planning is very useful as the basis of physical execution, so as to produce a good physical construction of talud infrastructure [5].

The formulation of the problem in this research is whether the construction of building talud existing in Aceh Singkil district is already safe against the style of bolsters, slip and capacity of land carrying capacity[6]-[8].

Knowing the effect of the safety factor due to the slip, bolsters, and the carrying capacity of the soil and the large decrease due to the consolidation of the clay layer and the load of embankment as well as the decreasing amount of time[9], [10].

\section{Methodology}

Methodology research used is by way of data retrieval in the field as a material planning technique talud, among others:

a. Data processing talud, conducted by analytic survey.

b. Research Sites of Gosong Village Telaga Barat District of North Singkil Aceh Singkil District. c. Research Time from January to April 2018.

d. Primary data obtained by direct observation to the field where the research location and data of coordination with consultant field.

e. Secondary data supporting data in research in the form of literature or literature, Terzaghi ground pressure, slope stability and decline.

The building of the talud is a rigid structure structure which can withstand both vertical and horizontal movements and if the collapse can still be used again besides the talud serves as a construction to protect and strengthen such as the structure of the cliff, the river slope, the embankment slope, which serves to keep the river bank against the current the flow of water and keep the flow of water from the edge of the river that can damage the cliffs of the earth wall, and so forth.

\section{Retaining Wall}

According to SuyonoSosrodarsono, 1980 retaining wall is a building constructed to prevent the collapse of steep soil or slopes where its stability can not be guaranteed by the slope itself.

\section{Type of Soil}

According Terzaghi\& Peck (1993) there are various types of soil, among others: gravel, sand, silt, clay and peat (peat soil). 


\section{Lateral Land Pressure (Active and Passive)}

The well-known method is Rankine and Coulomb method.

There are different types of soil pressure that can occur on the retaining wall:

1. Soil Pressure Silent.

According to Braja M. Das, 1993, the coefficient of soil pressure is silent, since $\sigma \mathrm{v}=\gamma . \mathrm{z}$ then the horizontal lateral moment of pressure is: $\sigma \mathrm{h}=\mathrm{Ko}$. $(\gamma . \mathrm{Z})$ and the magnitude of the total force: $\mathrm{Po}=1 / 2$. Ko. $\gamma$. H2

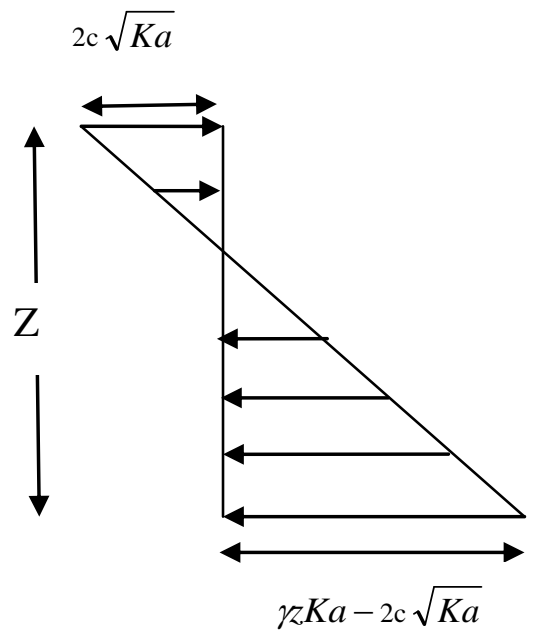

Fig 1: Active Soil Pressure Rankine

2. Active Land Pressure.

According to Rankine in lateral soil pressure analysis, Rankine (1857) has several assumptions, namely:

a. The soil in the plastic balance position, ie all elements of the soil in the right conditions will collapse.

b. The soil is not cohesive $(c=0)$.

c. The surface of the wall is considered perfectly slippery.

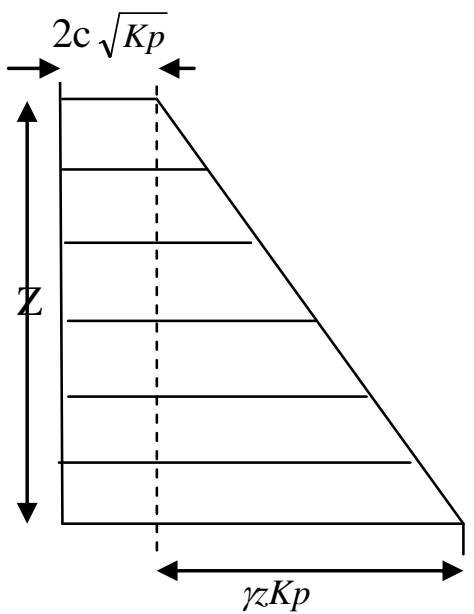

Fig 2: The Pressure of a Passive Rankine

\section{Active Pressure by Coulomb}

Some assumptions / assumptions according to Coulomb are:

1) The landslide and urug surface area are flat.

2) Friction forces are distributed along the landslide and ground friction coefficient $\mathrm{f}=$ tg. $\delta$.

3) The landslide is wedge-shaped, and is a unity.

4) There is friction between the retaining wall and the soil. Landslides move down along the rear of the retaining wall resulting in friction between walls and soil.

\section{Ground-Style-Wall-Retaining Wall}

The forces acting on the retaining wall, for example, are wide permeters such as for wall cantilever walls, semi creation, while for counter walls; the style is viewed in the space as wide as the distance between counterforts as the bottom image.

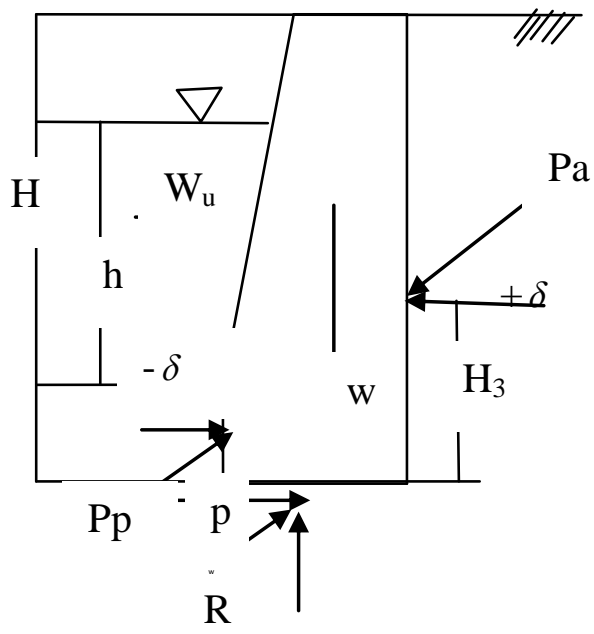

Fig 3: Ground-Style-Wall-Retaining Wall

\section{Ground Control Wall Stability Control}

In the preparation of the retaining wall, it begins by first determining the dimensions of the retaining wall. With this dimension and then rise stability.

It should be noted that the upper limb of the wall should not be from $0.3 \mathrm{~m}(\approx 12$ inches) as minimum. The depth $\mathrm{D}$ to the drain must be maintained not less than $0.6 \mathrm{~m}(\approx 2 \mathrm{ft})$. This basic enough is enough to allow not to scour.

3. Stability Control

In the planning of retaining wall, it is necessary to control the balance of retaining land copying several things include:

1. Stability Controls on the gulingdijari (toe)

2. Stability controls against underlying slip

3. Stability control of base carrying capacity

4. Control of the decline

5. Control of global stability

Table 1: Counting Procedure $\sum \mathrm{M}_{\mathrm{R}}$

\begin{tabular}{|c|c|c|c|c|}
\hline $\begin{array}{l}\text { Section } \\
\text { (1) }\end{array}$ & $\begin{array}{l}\text { Large } \\
\text { 2) }\end{array}$ & $\begin{array}{l}\text { Weight / Long Unit } \\
\text { Wall } \\
\text { (3) }\end{array}$ & $\begin{array}{l}\text { The moment } \\
\text { arm is measured } \\
\text { from the point } \\
\text { C } \\
\text { (4) }\end{array}$ & $\begin{array}{l}\text { Moment } \\
\text { at point } \\
\text { C } \\
(5)\end{array}$ \\
\hline $\begin{array}{l}1 \\
2 \\
3 \\
4 \\
5 \\
6\end{array}$ & $\begin{array}{l}\mathrm{A}_{1} \\
\mathrm{~A}_{2} \\
\mathrm{~A}_{3} \\
\mathrm{~A}_{4} \\
\mathrm{~A}_{5} \\
\mathrm{~A}_{6}\end{array}$ & $\begin{array}{l}W_{1}=\gamma_{1} * A_{1} \\
W_{2}=\gamma_{2} * A \\
W_{3}=\gamma_{c} * A_{3} \\
W_{5}=\gamma_{c} * A_{5} \\
W_{6}=\gamma_{c} * A_{6} \\
\mathrm{Pv} \\
\sum \mathrm{V}\end{array}$ & $\begin{array}{c}X_{1} \\
\mathrm{X}_{2} \\
\mathrm{X}_{3} \\
\mathrm{X}_{4} \\
\mathrm{X}_{5} \\
\mathrm{X}_{6} \\
\mathrm{~B}\end{array}$ & $\begin{array}{c}\mathrm{M}_{1} \\
\mathrm{M}_{2} \\
\mathrm{M}_{3} \\
\mathrm{M}_{4} \\
\mathrm{M}_{5} \\
\mathrm{M}_{6} \\
\mathrm{Mv} \\
\sum \mathrm{M}_{\mathrm{R}}\end{array}$ \\
\hline
\end{tabular}

4. Evaluation of Talud Technical Planning at the River Region of Aceh Singkil Regency

In analyzing the strength of river dikes in North Singkil Subdistrict, in the geotechnical field conducted in obtaining properties and soil characteristics using field investigation data as for the results obtained such as Figure 4. 


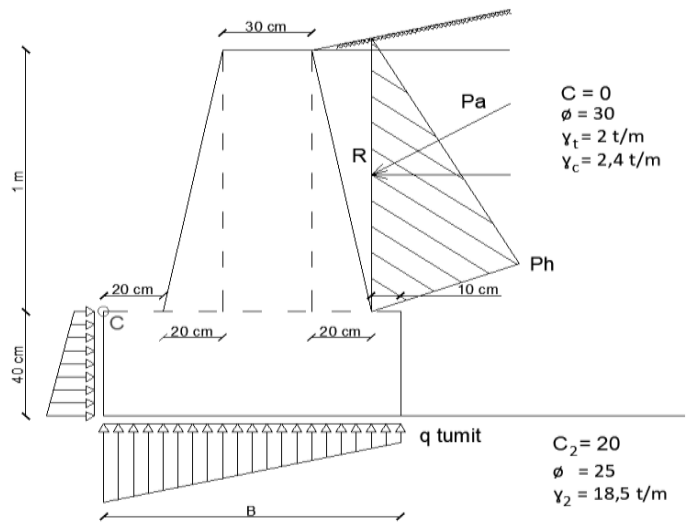

Fig 4: Dimension of Retaining Wall

Table 2: Calculation of the number of moments in holding down the Scroll in point $\mathrm{C}$

\begin{tabular}{|c|c|c|c|c|}
\hline Section & Large & Weight / Wall Length Unit (Yt* large) & The moment arm is measured from point $\mathrm{C}$ & Moments At point $\mathrm{C}$ \\
\hline 1 & 2 & 3 & 4 & 5 \\
\hline 1 & $(0,5 * 0,2 * 1)+(0,1 * 1)=0,2$ & $(2 * 0,2)=0,4$ & $(0,2+0,7)=0,9$ & $(0,4 * 0,9)=0,36$ \\
\hline 2 & $(0,5 * 0,3 * 0,173)=0,026$ & $(2 * 0,026)=0,52$ & $(0,15+0,7)=0,85$ & $(0,52 * 0,85)=0,442$ \\
\hline 3 & $(0,5 * 0,2 * 1)=0,1$ & $(0,1 * 2,4)=0,24$ & $(0,067+0,7)=0,767$ & $(0,24 * 0,767)=0,182$ \\
\hline 4 & $0,3 * 1)=0,3$ & $(0,3 * 2,4)=0,72$ & $(0,15+0,3)=0,45$ & $(0,72 * 0,45)=0,324$ \\
\hline 5 & $(0,5 * 0,2 * 1)=0,1$ & $(0,1 * 2,4)=0,24$ & $(0,067+0,2)=0,267$ & $(0,24 * 0,267)=0,064$ \\
\hline 6 & $0,4 * 1)=0,4$ & $(0,4 * 2,4)=0,96$ & 0,5 & $(0,96 * 0,5)=0,48$ \\
\hline $\mathrm{PV}$ & & 0,167 & 1 & $(0,167 * 1)=0,167$ \\
\hline$\sum \mathrm{V}$ & & 3,247 & $\sum \mathrm{MR}$ & 2,021 \\
\hline
\end{tabular}

\section{Control Stability to Bolster}

Moments of style $\mathrm{Pv} \mathrm{C}$ emphasis is

$$
\begin{aligned}
M v & =P v B \\
& =P a \cdot \sin \alpha * B \\
& =0,333 * \sin 30^{0} * 1 \\
& =0,167
\end{aligned}
$$

The safety factor against bolsters,

$$
\begin{aligned}
& F S_{(\text {blosters })}=\frac{M_{1}+M_{2}+M_{3}+M_{4}+M_{5}+M_{6}+M_{v}}{P a \cos \alpha \frac{H^{\prime}}{3}} \\
& F S_{(\text {blosters })}=\frac{\sum M R}{0,333 * \cos 30^{0} * \frac{1,4}{3}}=\frac{2,021}{0,134} \\
& F S_{\text {(blosters) }}=15,08>1,5 \text { talud scure with bolsters }
\end{aligned}
$$

\section{Stability Control against Slippers}

$$
\begin{aligned}
F s_{(\text {slip })} & =\frac{\sum V \cdot \tan \phi_{2}+B \cdot c_{2}+P p}{P a \cdot \cos \alpha} \\
& =\frac{\sum F \cdot R^{\prime}}{P_{h}} \\
& =\frac{35,850}{0,288}>1,5 \\
& =124,479>1,5 \quad \text { scure with the slip. }
\end{aligned}
$$

\section{Stability Controls on Supporting Capacity}

A value $\mathrm{Nc}, \mathrm{Nq}, \mathrm{N}$ and taken from the table to support power factor, then the retrieved

$\mathrm{NC}=20.72, \mathrm{Nq}=10.6610 .88, \mathrm{~N}=$ and $=0.45$ $q u=c N c$ Fcs Fcd Fci $+q N q$ Fqs Fqd Fqi

$$
\begin{aligned}
& +\frac{1}{2} \gamma B N_{\lambda} F_{\gamma s} F_{\gamma d} F_{\gamma i} \\
q u= & 20 *(20,72) *(1,148) *(0,636) \\
& +7,4 *(10,66) *(1,199) *(0,891) \\
& +0,5 *(18,5) *(1,081) *(10,88) *(1) *(0,891) \\
= & 302,565+84,272+96,934 \\
= & 483,771
\end{aligned}
$$

$$
\begin{aligned}
F s & =\frac{q_{u}}{q_{\max }}>3 \\
& =\frac{483,771}{2,984}>3 \\
& =162,122>3 \mathrm{sec} \text { ure from power sup port }
\end{aligned}
$$

$$
\begin{aligned}
K_{p} & =\tan ^{2}\left(45+\frac{\phi}{2}\right) \\
& =\tan ^{2}\left(45+\frac{30}{2}\right)=3 \\
K_{a} & =\tan ^{2}\left(45-\frac{\phi}{2}\right) \\
& =\tan ^{2}\left(45-\frac{30}{2}\right)=0,333
\end{aligned}
$$




$$
\begin{aligned}
& F_{S \text { (bolsters) }}=\frac{\sum M R}{\sum M o} \\
& \mathrm{~Pa} \quad=\frac{1}{2} \mathrm{Ka}_{\mathrm{N}} \mathrm{H}^{2} \\
& =\frac{1}{2}\left(0,333 * 2 *(1)^{2}=0,3333\right. \\
& \sum M o=P_{h}\left(\frac{H^{\prime}}{3}\right) \quad \Rightarrow P_{h}=P a * \cos \alpha \\
& =0,288 *\left(\frac{1,4}{3}\right) \quad=0,333 * \cos 30^{\circ} \\
& =0,134 \mathrm{t} / \mathrm{m} \quad=0,288 \\
& P V \quad=P_{a} * \sin \alpha \quad \Rightarrow H^{\prime}=1+0,4=1,4 \\
& =0,333 * \sin 30^{0}=0,167
\end{aligned}
$$

\section{Conclusion}

From the evaluation result, the talud condition in the field of talud size need not be changed and the result of the planning show good result. For the result of control analysis of collapse of bolsters where FS guling $=15.08$ this value is greater than the safety factor, this shows the condition of the talud safe against bolsters. For the stability control of the slip where the maximum force force, where the only thrust causing the horizontal component of active force $(\mathrm{Pa}=0.333)$ results in FS (flex) $=124,479$ is greater than the safety factor which causes the talud to secure against the slip. For the control of the stability of the carrying capacity, where the eccentricity value $(e=-0.081)$ is less than $1 / 6$ then the qmin value becomes positive, since the value of e $<1 / 6$, indicates the wall dimension need not be resized, ground support (FS (carrying capacity) $=162.122$ ) This value is greater than FS security means that the talud securely holds the load carrying capacity provided.

\section{References}

[1] E. Gunawan, Pengendalian Bahan Baku Pengolahan. Medan: Tim Retooling LPP Kampus, 2010.

[2] A. Hasibuan et al., "Performance analysis of Supply Chain Management with Supply Chain Operation reference model," vol. 1007, pp. 1-8, 2018.

[3] A. Hasibuan, A. Hasibuan, A. R. Suleman, I. S. Poneni, L. Parinduri, and O. K. Sulaiman, "Analysis of effect of production costs and employment on sale of kurma salak," Int. J. Eng. Technol., vol. 7, no. 2.9, pp. 56-60, Mar. 2018.

[4] Y. Yusmartato, Y. Yusmartato, L. Parinduri, A. Hasibuan, . R., and O. K. Sulaiman, "Optimize effort oil collection in fat pit palm oil factory tanjung seumantoh," Int. J. Eng. Technol., vol. 7, no. 2.9, pp. 41-43, Mar. 2018.

[5] Y. Yusniati, T. Hernawati, L. Parinduri, O. K. Sulaiman, and S. Suliawati, "Analysis of current overflow disturbance towards neutral grounding resistance condition," vol. 7, pp. 66-70, 2018.

[6] D. I. S. Sosrodarsono, Mekanika Tanah \& Teknik Pondasi. 1981.

[7] I. S. Hs, Pondasi Tiang Pancang, 1st ed. Surabaya: Sinar Jaya, 1991.

[8] B. M.dass, Mekanika Tanah. Dinas Pekerjaan, 1991.

[9] A. Hasibuan, Metodologi Penelitian. 2013.

[10] O. K. Sulaiman et al., "Bellman Ford algorithm-in RoutingInformation Protocol ( RIP ),” vol. 1007, pp. 1-9, 2018. 